\title{
BIODEGRADABLE SISAL FIBRE EXTRACTOR AND STUDY THE FIBRE QUALITY THROUGH VARIED SISAL LEAF SOCKING PERIODS
}

\author{
A K Murthy \\ Professor, Department. of M.E, AMC Engineering College, Bangalore, India.
}

\section{Geetha T M}

Assistant Professor, Department. of M.E, AMC Engineering College, Bangalore, India.

\author{
Praneeth kumar S, Pavan kumar B N, Rajshekar, Nitin M Achari \\ Students, M.E, AMC Engineering College, Bangalore, India.
}

\begin{abstract}
The demand of natural fibres is increasing in the world for industrial uses to make high value products.

An enormous potential of sisal fibre is used in making ropes, paper, carpets, cloth $\&$ handicrafts.

The aim of this study is to design \& fabricate a small scale portable sisal fibre extractor for extracting fibre from sisal leaves.

However, hand processing of sisal leaves is a tedious, laborious \& slow exercise resulting in low productivity \& low quality fibre.

This machine has a great potential and needs to be commercialised in sisal growing areas of the country
\end{abstract}

Key words: Sisal Fibre, Fibre Quality, Sisal, Leaf Socking.

Cite this Article: A K Murthy, Geetha T M, Praneeth Kumar S, Pavan Kumar B N, Rajshekar, Nitin M Achari, Biodegradable Sisal Fibre Extractor and Study the Fibre Quality Through Varied Sisal Leaf Socking Periods, International Journal of Advanced Research in Engineering and Technology, 10 (3), 2019, pp 128-139.

http://iaeme.com/Home/issue/IJARET?Volume=10\&Issue=3

\section{INTRODUCTION}

Knowing the huge potential of sisal fibres. Over a period of time, machines have been invented to extract fibres from the sisal leaves. However these machine successfully extract fibre from leaves but the major obstacle is that the machine is large in size, and applicable for large scale commercial purpose.

The cost of the machine is high and the area required for installation is more. To overcome all the above problems, we have designed and fabricated a small scale portable sisal fibre 
extractor. Which consists of a rectangular frame on which the entire setup is placed. To the one end of the rectangular frame four bolts of 12 inches of length are placed facing upwards. Two metal rollers are used. Universal hub bearings are connected to the ends of the rollers. The bearings with the rollers are bolted to the L shaped angle plates. Holes are drilled on the $\mathrm{L}$ shaped angle plate, measuring the distance between the bolts placed onto the rectangular frame. The L shaped angle plates are fitted into the bolts onto the rectangular frame and tightened with nuts. The distance between the two rollers can be increased or decreased by loosening or tightening the nuts.

A belt pulley of one feet diameter is fitted to the upper roller. To the other end of the rectangular frame a single phase induction motor of $2 \mathrm{HP}$ is fitted. Both the rollers and the motor are connected through $\mathrm{v}$ belt.

When the motor is connected to the power supply. The motor (driver) rotates the roller (driver). The upper roller rotates in clockwise direction and the lower roller remains constant. $2 \mathrm{~mm}$ of gap is maintained between the two rollers.

The leaves are fed in between the two rollers and the leaves gets crushed and comes out from the other side which is collected and further washed in clean water, dried in sun and combed to extract fibres.

However the machine designed and developed is a semi-automated and applicable only for small scale purpose.

Mild steel is used for the fabrication of the entire machine.

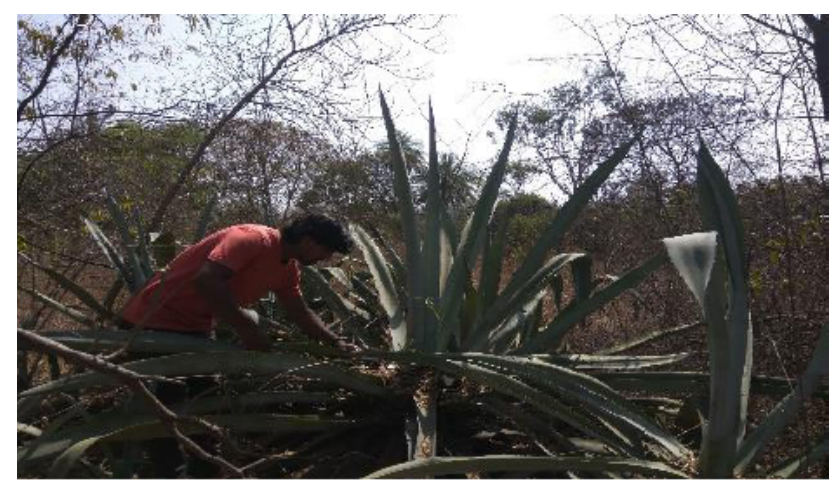

Figure 1

\section{LEAF SPECIFICATION}

- Length : $550 \mathrm{~mm}$ to $1600 \mathrm{~mm}$

- Width : $45 \mathrm{~mm}$ to $120 \mathrm{~mm}$

- Weight : $0.27 \mathrm{~kg}$ to $0.75 \mathrm{~kg}$

- Thickness : $2 \mathrm{~mm}$ to $40 \mathrm{~mm}$

- Colour : green

\section{OBJECTIVE}

To design \& fabricate a suitable machine for extracting fibers from sisal leaves.

To study the process ability of the machine and successfully extract the fibers without damaging their essential properties.

To analyse the structure $\&$ properties of extracted fibers.

To analyse the suitability of the extracted fibers for various applications. 


\section{CONCEPTUAL SKETCHES}

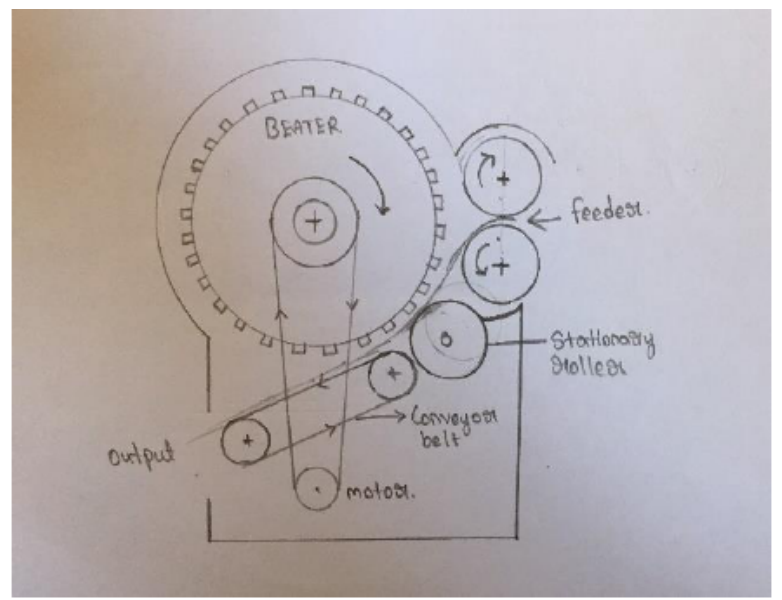

Figure (a)

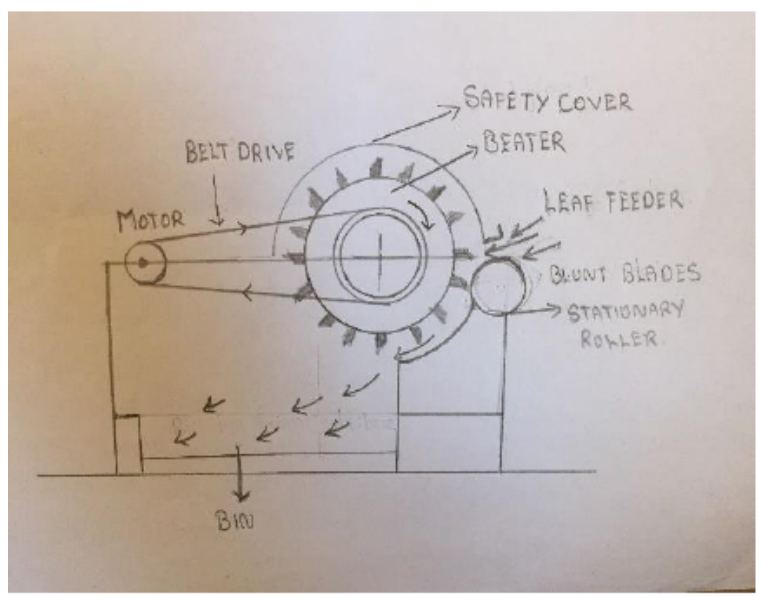

Figure (c)

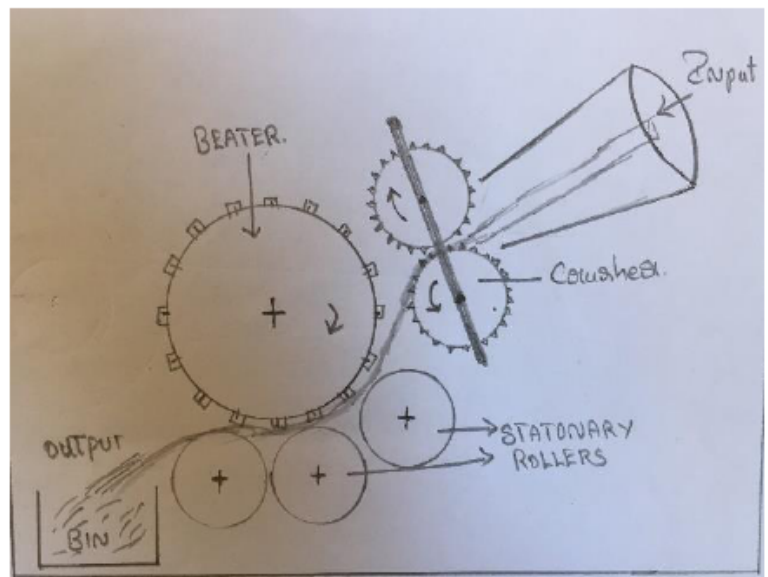

Figure (b)

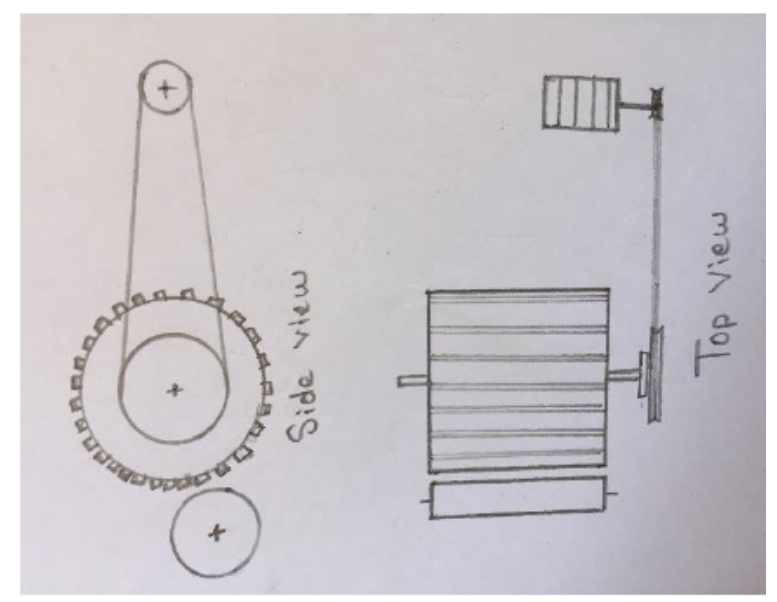

Figure (d)

\section{METHODOLOGY}

Sisal leaf is fed in between the two rotating rollers, rotating in opposite direction. $2 \mathrm{~mm}$ of gap is maintained between 2rollers. The leaf has a varying thickness, the tip of the leaf is $2 \mathrm{~mm}$ and goes on increasing until the butt. The leaf gets crushed when it comes in contact between the 2rollers and the pulp material gets separated from the leaf. The fibres are collected from other side of the rollers. Then the obtained fibres are washed in clean water to remove the remaining residue on the fibres, dried in sun and combed to obtain good quality fibres 
Biodegradable Sisal Fibre Extractor and Study the Fibre Quality Through Varied Sisal Leaf Socking Periods

\section{FABRICATION}

\section{Frame}

\section{Top view}

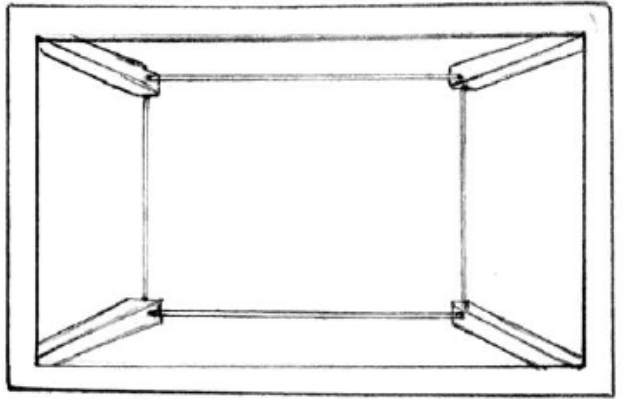

Front View

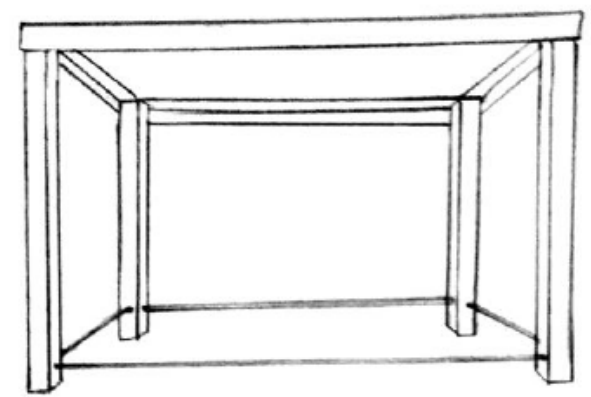

Side view

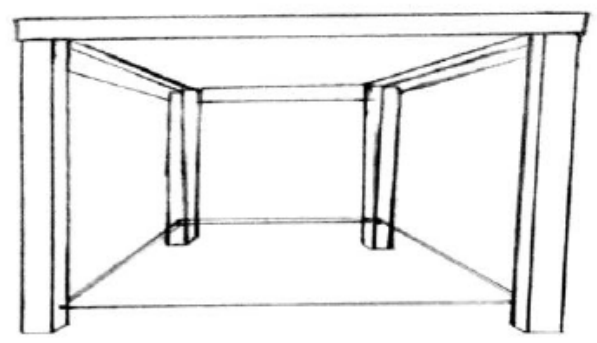

length : 920mm /width : 450mm height : $730 \mathrm{~mm}$

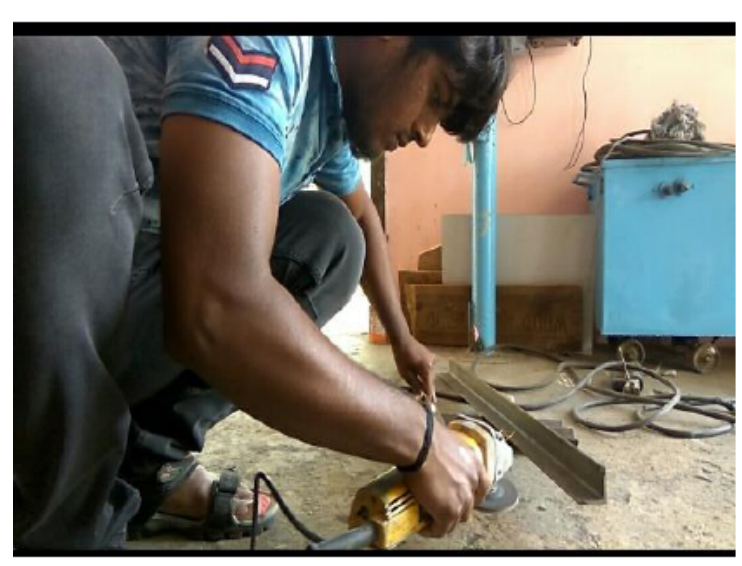

Figure 2
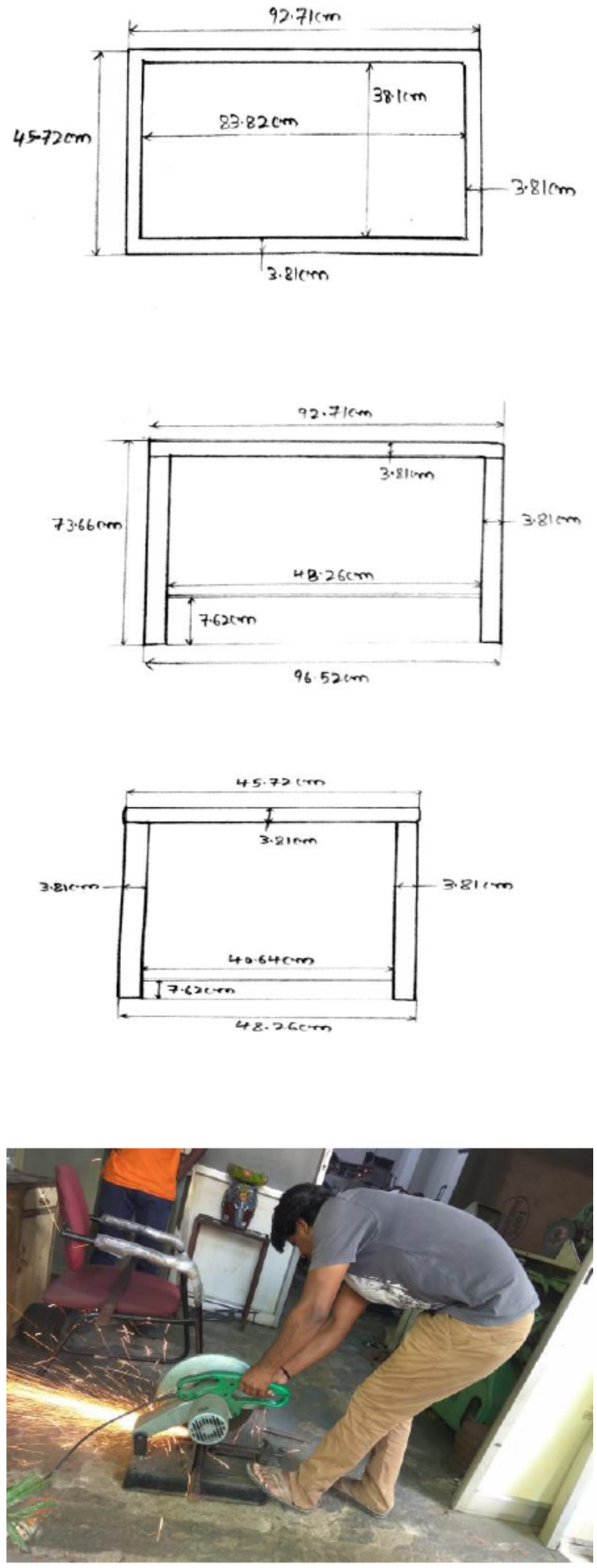

Figure 3 
A K Murthy, Geetha T M, Praneeth Kumar S, Pavan Kumar B N, Rajshekar, Nitin M Achari

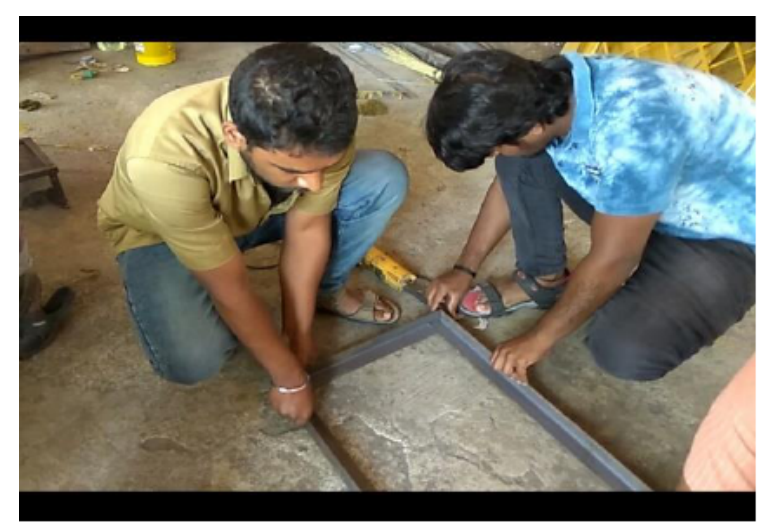

Figure 4

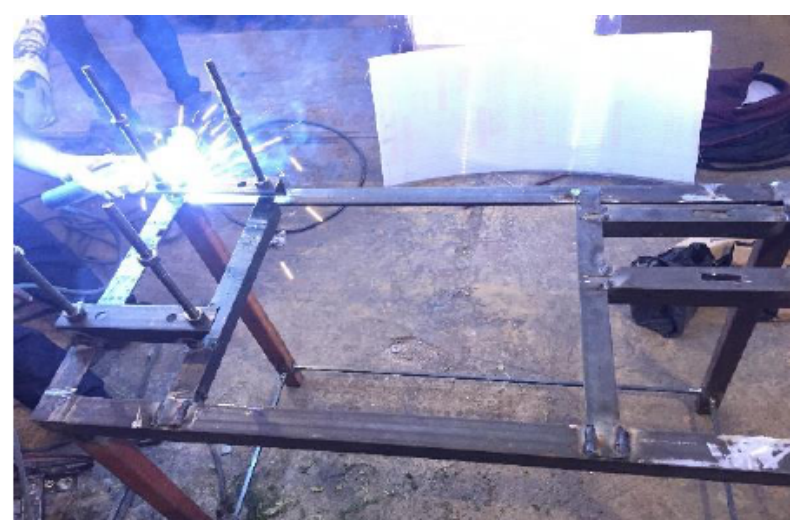

Figure 5

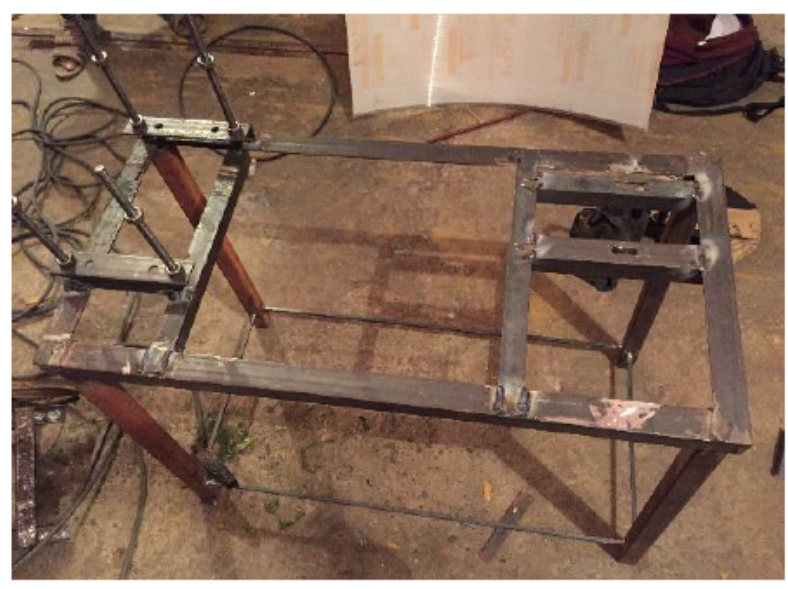

Figure 6

\section{MACHINE COMPONENTS}

\section{Bearings}

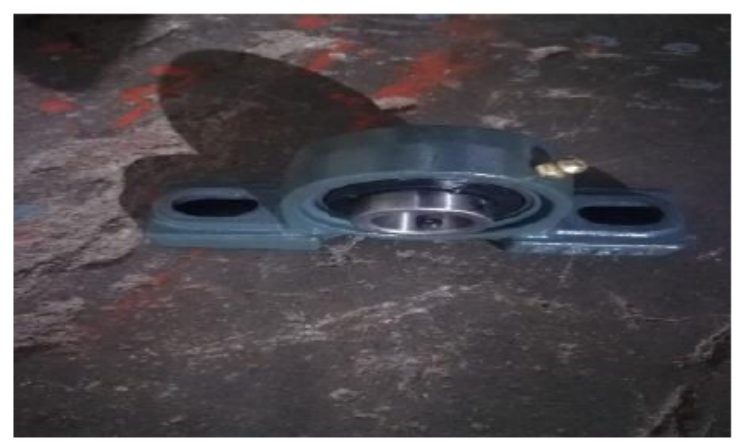

Figure 7

materials made : cast iron housing, chrome steel bearing

Housing width : $38 \mathrm{~mm}$

Inner dia : $20 \mathrm{~mm}$

Bearing type : Extended inner race with set screw 


\section{Pully}

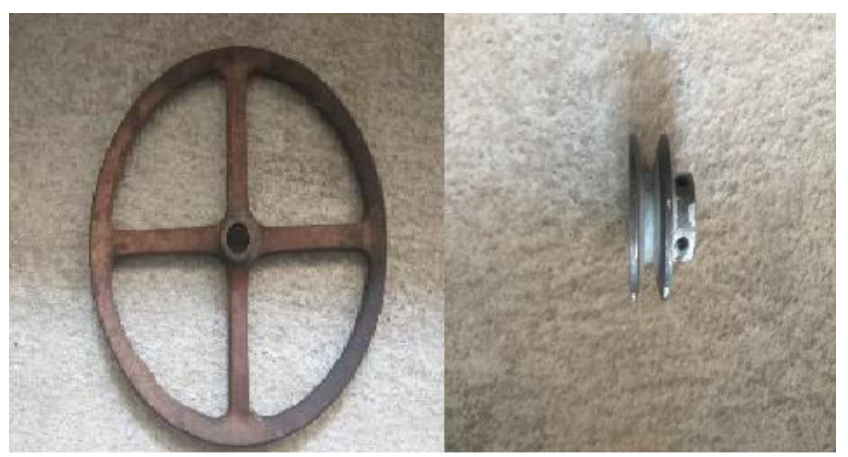

Figure 8

BIG Outer dia : 305mm

Inner dia : $20 \mathrm{~mm}$

SMALL Outer dia : 76mm

Inner dia : $20 \mathrm{~mm}$

\section{Motor}

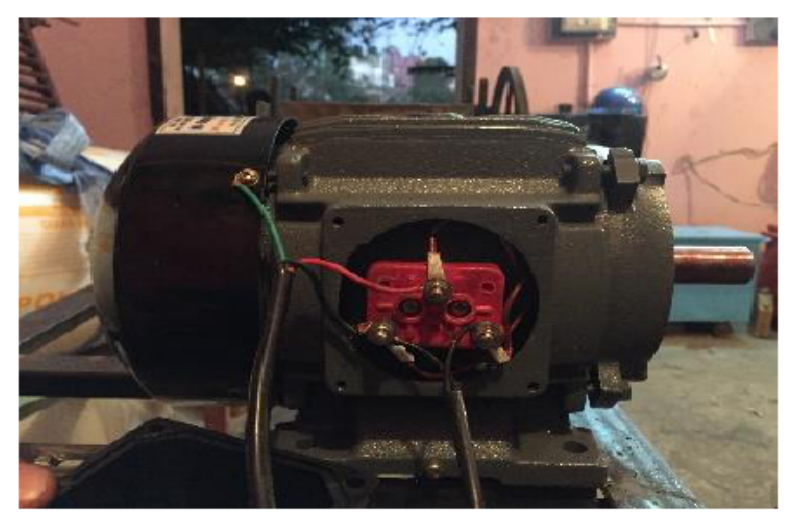

Figure 9

3 phase induction motor

$2 \mathrm{hp}$

440 volts

$1480 \mathrm{rpm}$

\section{Belt}

Type : v-belt

B series 71

\section{ASSEMBLY AND WORKING PRINCIPLE}

Sisal fibre extractor fabricated is one of the unique type where the entire machine can be dismantled. The working parts are setup on the rectangular frame. To the top left end of the frame two rollers are placed whose ends are connected to the universal hub bearings and held together by the bolts. Where the gap between the two rollers can be increased or decreased by loosening or tightening the nuts. Pulley is connected to the top roller and the lower roller. To the top right of the rectangular frame an electric motor is fixed and a $v$ belt is connected from 
the motor to the upper pulley. To the bottom right of the rectangular frame another electric motor is fixed and a $\mathrm{v}$ belt is connected from the electric motor to the lower pulley.

Both the motors run in clock wise direction when connected to the power supply.

\section{Working principle}

When both the motors are connected to the power supply. They rotate in clockwise direction. As the $\mathrm{v}$ belts are connected to the two rollers both the rollers rotate in opposite direction to each other. Maintaining the gap of $2 \mathrm{~mm}$ in between the rollers, leaf gets easily crushed and fibres from the leaf gets separated from the pulp material.

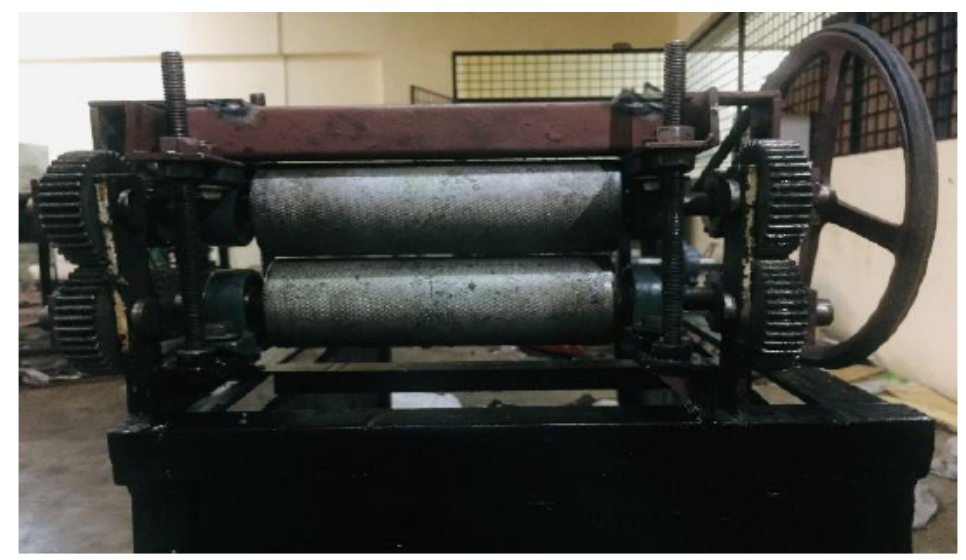

Figure 10

\section{SISAL PLANT}

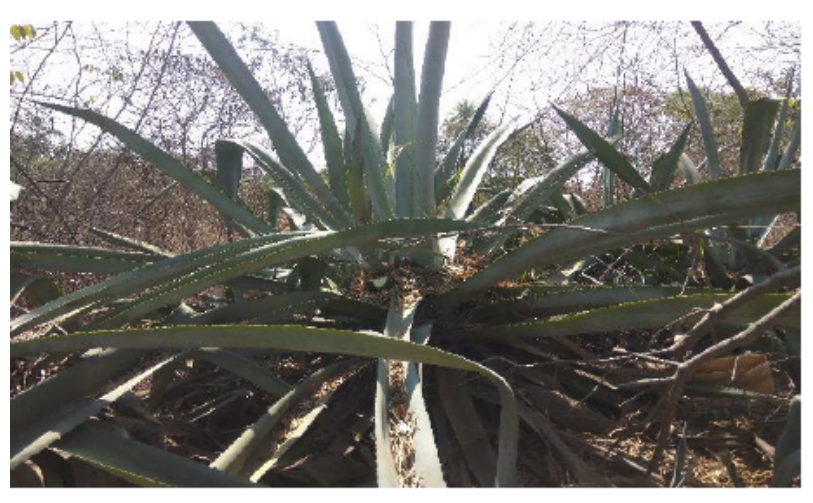

Figure 11

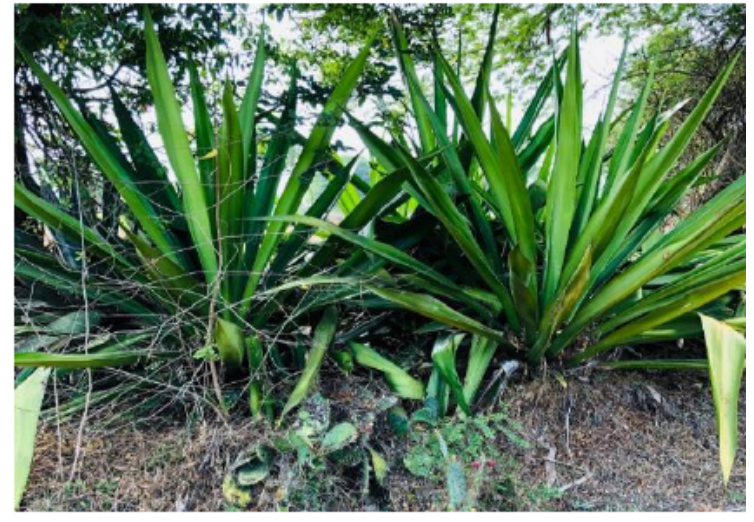

Figure 12

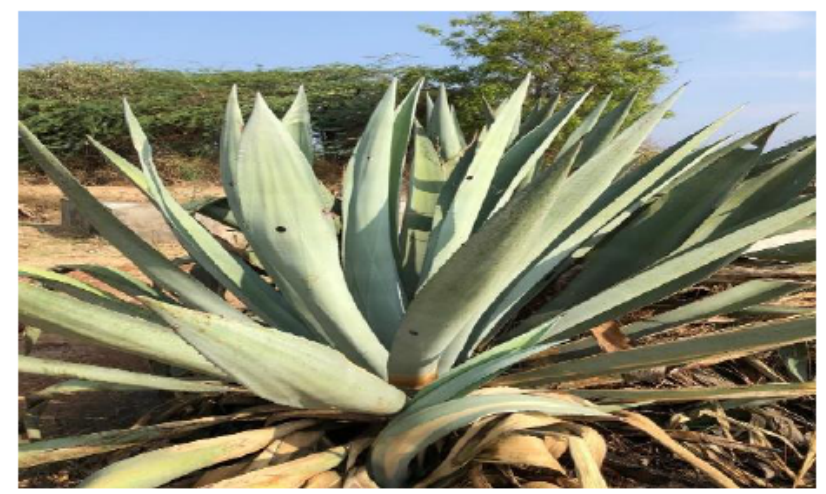

Figure 13 
Many plants are grown for their flowers and fruits. But there is a plant named sisal which is grown for its high fibre content. Sisal belongs to a family of asparagaceae. Sisal is also called by another name agave sisalana. Sisal found its origin in southern Mexico but it is largely cultivated in many other countries such as Brazil, china, Kenya, Madagascar etc...

Sisal plant was grown for the purpose of fencing and burnt as fire wood, before the people knew the fibre that can be extracted from the plant. The sisal plant has a life span of 7 to 10 years and produces 200 to 250 leaves. Sisal gets harvested for the first time after 2 to 3 years of plantation but subsequently harvested after 6 to 12 months.

Sisal is a plant which can be grown in wasteland, dry land and in saline soil and it has a special quality of withstanding severe drought conditions. In India, sisal is mainly found in Orissa, Maharashtra and southern states. Approximately 1000 tonnes of sisal is produced in India every year.

CHEMICAL COMPOSITION OF SISAL FIBER MACHINING PROCESS[1]

\begin{tabular}{|l|c|}
\hline \multicolumn{1}{|c|}{ COMPOSITION } & AMOUNT (\%) \\
\hline Cellulose & $68-80$ \\
\hline Hemicellulose & 15 \\
\hline Lignin & $5-17$ \\
\hline Wax & 0.26 \\
\hline Moisture & 8 \\
\hline
\end{tabular}

\section{COMPARISON OF MECHANICAL PROPERTIES BETWEEN TEXTILE FIBRES[1]}

\begin{tabular}{|l|c|c|c|c|}
\hline \multicolumn{1}{|c|}{ Fibres } & $\begin{array}{c}\text { Tenacity } \\
\text { (cN/text) }\end{array}$ & $\begin{array}{c}\text { Strain } \\
(\mathbf{\%})\end{array}$ & $\begin{array}{c}\text { Initial } \\
\text { Modulus } \\
\text { (N/text) }\end{array}$ & $\begin{array}{c}\text { Work fracture } \\
\text { (mN/text) }\end{array}$ \\
\hline Agave Americana & $21-41$ & $2-4$ & $0.2-1.45$ & $7.7-25.4$ \\
\hline Sisal & $40-49$ & $2-3$ & $25-26$ & - \\
\hline Flax & $25-26$ & $2.7-3.3$ & 18 & 8 \\
\hline Jute & $29-56$ & $1.2-1.9$ & 17.2 & 2.7 \\
\hline Cotton & $28-48$ & $3-10$ & 5 & 10.7 \\
\hline E glass & 82 & 2.5 & 29.4 & 9.8 \\
\hline Polyester (HP) & 61 & 7 & 13.2 & 22 \\
\hline
\end{tabular}

\section{Production Scenario}

Sisal is mainly grown in arid and semi-arid regions of Andhra Pradesh, Bihar, Orissa, Karnataka, Maharashtra and West Bengal. About 275 species are distributed in tropical regions of India. The major sisal cultivation districts of different states in India are given below. [4]

\begin{tabular}{|l|l|}
\hline \multicolumn{1}{|c|}{ State Name } & \multicolumn{1}{c|}{ District } \\
\hline Karnataka & Chamraj nagar \\
\hline Tamilnadu & Vellore \\
\hline Uttarakhand & Kumaon, kotdwar \\
\hline Madhya Pradesh & Durg, Bhopal \\
\hline Maharastra & Ahemadnagar \\
\hline West Bengal & Midnapur(E) \\
\hline Jammu \& Kashmir & $\begin{array}{l}\text { Bhalwal, Jammu, ratnapur } \\
\text { sarar, kathua }\end{array}$ \\
\hline
\end{tabular}


A K Murthy, Geetha T M, Praneeth Kumar S, Pavan Kumar B N, Rajshekar, Nitin M Achari

\section{FIBRE EXTRACTION PROCESS}

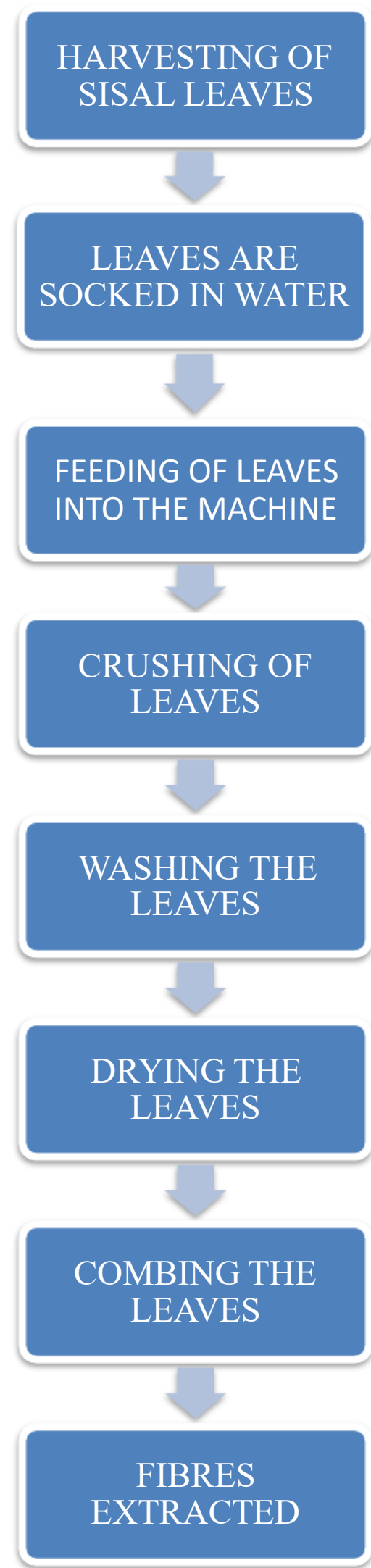


The sisal leaves are socked in water for 10 days. The purpose of socking the leaf is that the pithy matter which is present in the leaf gets separated and the process for the extraction of fibre gets easier. The socked leaf is fed into the machine.

The machine consists of two main roller, bearings are connected to the ends of the rollers. The rollers are held together by the bolts and fixed to one end of the rectangular frame.

Motor is fixed to the other end of the rectangular frame, $v$ belt is connected between the two pulley. The larger pulley is fixed to the roller and the smaller pulley is fixed to the motor.

Leaf is fed in between the two rollers which rotate in opposite direction and gets crushed, the green leaf material gets removed and the fibre gets extracted.

The extracted fibre is washed in water and dried in sun.

\section{FIBRE EXTRACTED}

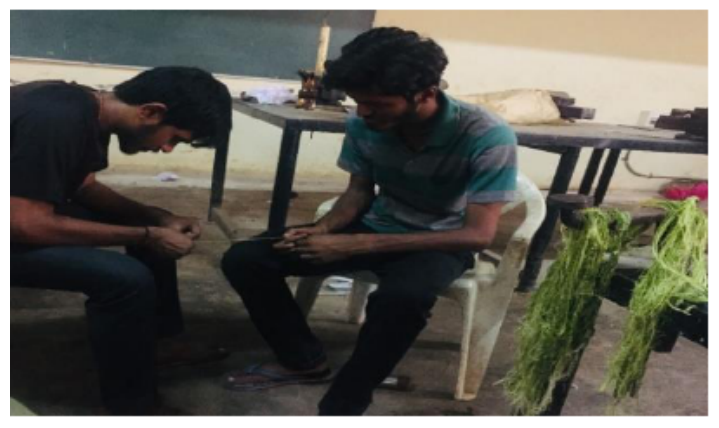

Figure 14

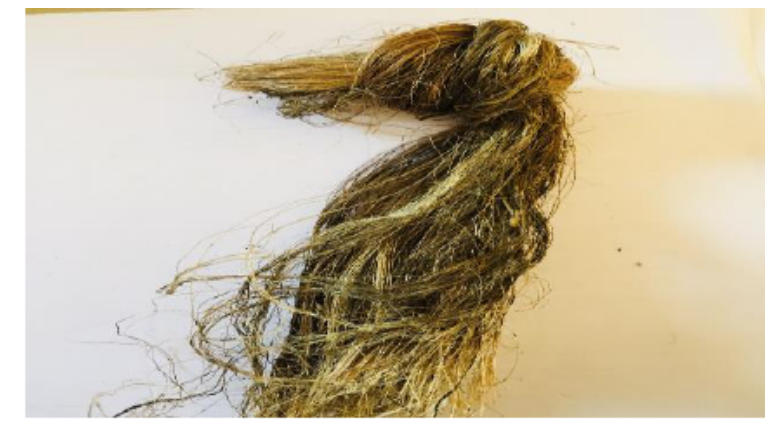

Figure 15

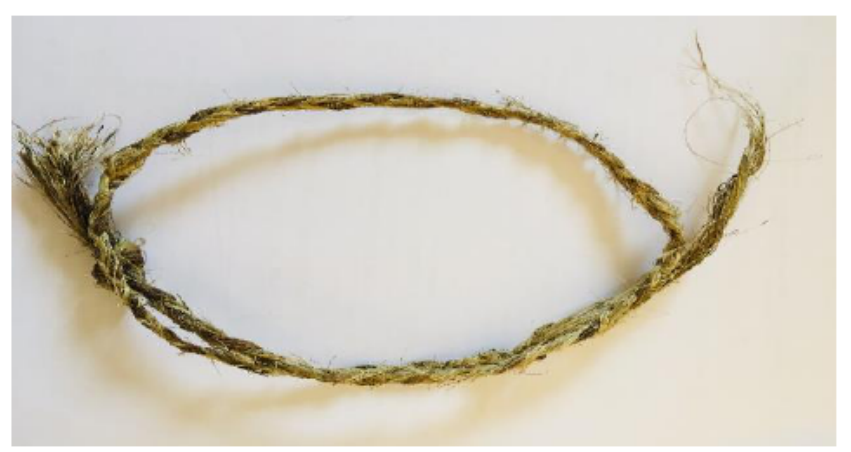

Figure 16

\section{OBJECTIVE OF THE STUDY}

- To study the obtained fiber quality under various conditions.

- To study the performance of the extractor.

- To use the extracted fibre for various application.

\section{STUDYING THE PERFORMANCE}

Knowing the performance of the machine can help us in future study and improvement or betterment of the machine.

Firstly, the leaves are cut from the sisal plant and directly fed into the extractor and the percentage of the fibre successfully extracted is noted.

Then the fresh leaves are socked in water for five days and then fed into the extractor, then the percentage of the fibre extracted is noted. In the same way the leaves are socked for 10, 15 $\& 20$ days and fibres are extracted and the percentage of the fibres are noted down. 
A K Murthy, Geetha T M, Praneeth Kumar S, Pavan Kumar B N, Rajshekar, Nitin M Achari

The more percentage of the fibre obtained for so many number of days of socking will be followed in the future.

\section{COMPARISON}

\begin{tabular}{|c|c|c|l|l|}
\hline $\begin{array}{c}\text { Sl } \\
\text { No }\end{array}$ & $\begin{array}{c}\text { No. of days leaf } \\
\text { socked in water }\end{array}$ & $\begin{array}{c}\text { \%o of fibre } \\
\text { obtained }\end{array}$ & $\begin{array}{c}\text { Quality of the } \\
\text { fibre }\end{array}$ & Image \\
\hline 1 & 0 & $5 \%$ & Not good & \\
\hline 2 & 5 & $30 \%$ & Ok & \\
\hline 3 & 10 & $55 \%$ & Moderate & \\
\hline 4 & 15 & $70 \%$ & good & \\
\hline 5 & 20 & $80 \%$ & Good & \\
\hline
\end{tabular}

\section{OUTCOME}

- A small scale portable sisal fibre extractor has been fabricated.

- Fibres has been extracted from the machine fabricated.

- The machine can be easily transportable as the weight is below $100 \mathrm{~kg}$ and the space required for installation is very minimal.

\section{POSSIBLE APPLICATION}

The fibres extracted can be used for making,

- Cordage such as rope, twine, and yarn.

- Composite materials such as automobile components, construction roofing and paneling materials.

- Woven materials such as carpets, bags and buffing cloth ect..

- Organic fertilizer, animal feed stock, industrial alcohol (ethanol), pharmaceutical products (insulin), pulp and paper (speciality paper, reinforcement) and energy generation (biogas, electricity) [4]

\section{LITERATURE REVIEW}

\begin{tabular}{|l|l|c|}
\hline \multicolumn{1}{|c|}{ Title } & \multicolumn{1}{c|}{ Authors } & Year \\
\hline $\begin{array}{l}\text { Design and development } \\
\text { of portable sisal } \\
\text { decorticator }\end{array}$ & $\begin{array}{l}\text { Tanveer Ahmad, Sultan } \\
\text { Mahmood, Zulfiquar ali, } \\
\text { Muhammad Azeem Khan }\end{array}$ & 2017 \\
\hline $\begin{array}{l}\text { Design and development } \\
\text { of plantain fibre } \\
\text { extraction machine }\end{array}$ & $\begin{array}{l}\text { B.U.Oreko, S.Okiy, } \\
\text { E.Emagbetere, and } \\
\text { M.Okwu }\end{array}$ & 2018 \\
\hline $\begin{array}{l}\text { Studies on physical } \\
\text { properties of sisal plant } \\
\text { leaves }\end{array}$ & $\begin{array}{l}\text { Naik R.K, Dash R.C, } \\
\text { Behera D and Goel A.K }\end{array}$ & 2016 \\
\hline $\begin{array}{l}\text { Portable sisal decorticator } \\
\text { for Kenyan formers }\end{array}$ & $\begin{array}{l}\text { Benjamin J. Snyder, Jeo } \\
\text { Bussard, } \\
\text { Jim Dolak, Timweiser }\end{array}$ & 2006 \\
\hline
\end{tabular}


Biodegradable Sisal Fibre Extractor and Study the Fibre Quality Through Varied Sisal Leaf Socking Periods

\section{REFERENCES}

[1] Hulle, Ashish \& Kadole, Dr. P \& Katkar, Pooja. Agave Americana Leaf Fibers. Fibers. 3. (2015). 64-75. 10.3390/fib3010064.

[2] Nadia Abbas Ali, Ikram Atta AL-Ajaj and Farah Tariq Mohammed Noori, Effect of Nano Sio2 on Some Mechanical Properties of Biodegradable Polylactic Acid, International Journal of Mechanical Engineering and Technology (IJMET), Volume 5, Issue 2, February (2014), pp. 0107

[3] Naik, Ranjan. Research Article Studies on Physical Properties of Sisal (Agave Sisalana) Plant Leaves. 8. (2016).

[4] Mubarak, Y.A, Effects of Biodegradable Polypropylene Additive on the Impact Strength and Spherulites Growth Rate of Isotactic Polypropylene, International Journal of Mechanical Engineering and Technology, 9(5), 2018, pp. 109-121.

[5] P. Srinivasakumar, M. J. Nandan, Dr. C. Udaya kiran, Dr. K. Prahlada Rao, studies on "Sisal and Its Potential for Creating Innovative Employment Opportunities and Economic Prospects" on Sep 2013.

[6] Atluri Praneeth, Pramod Kumar K V S, Raghavendra Ravikiran K and Prakash Marimuthu K, Evaluation of Briquettes made of Biodegradable materials as an alternate source of energy, International Journal of Mechanical Engineering and Technology 8(11), 2017, pp. 977-983

[7] Laxmikanta Nayak, D. Nag, S. Das, Deb Prasad Ray and Lakshamanan Ammayappan, Utilisation Of Sisal Fibre (Tion Of Sisal Fibre (Agave Sisalana L.) - A Review, Agri. Review, 32 (2): $150-152,2011$. 